\title{
Nesfatin-1 Influences the Excitability of Gastric Distension-Responsive Neurons in the Ventromedial Hypothalamic Nucleus of Rats
}

\author{
Hongzhen FENG ${ }^{1}$, , Qiaoling WANG ${ }^{1}$, Feifei GUO ${ }^{1}$, Xiaohua HAN $^{1}$, Mingjie PANG $^{2}$, \\ Xiangrong $\mathrm{SUN}^{1}$, Yanling $\mathrm{GONG}^{3}$, $\mathrm{Luo} \mathrm{XU}^{1 *}$ \\ *These two authors contributed equally to this work.
}

${ }^{1}$ Department of Pathophysiology, Medical College of Qingdao University, Qingdao, Shandong, PR China, ${ }^{2}$ Otolaryngological Department, Qingdao Municipal Hospital (Group), Qingdao, Shandong, PR China, ${ }^{3}$ Department of Pharmacy, College of Chemical Engineering, Qingdao University of Science and Technology, Qingdao, Shandong, PR China

Received March 12, 2016

Accepted October 3, 2016

On-line December 16, 2016

\section{Summary}

The present study investigated the effects of nesfatin-1 on gastric distension (GD)-responsive neurons via an interaction with corticotropin-releasing factor (CRF) receptor signaling in the ventromedial hypothalamic nucleus $(\mathrm{VMH})$, and the potential regulation of these effects by hippocampal projections to $\mathrm{VMH}$. Extracellular single-unit discharges were recorded in VHM following administration of nesfatin-1. The projection of nerve fibers and expression of nesfatin- 1 were assessed by retrograde tracing and fluoro-immunohistochemical staining, respectively. Results showed that there were GD-responsive neurons in $\mathrm{VMH}$; Nesfatin-1 administration and electrical stimulation of hippocampal CA1 sub-region altered the firing rate of these neurons. These changes could be partially blocked by pretreatment with the non-selective CRF antagonist astressin- $B$ or an antibody to NUCB2/nesfatin-1. Electrolytic lesion of CA1 hippocampus reduced the effects of nesfatin-1 on $\mathrm{VMH}$ GD-responsive neuronal activity. These studies suggest that nesfatin-1 plays an important role in GD-responsive neuronal activity through interactions with CRF signaling pathways in $\mathrm{VMH}$. The hippocampus may participate in the modulation of nesfatin-1-mediated effects in VMH.

\section{Key words}

Nesfatin-1 • Ventromedial hypothalamic nucleus • Hippocampus • Gastric distension responsive neurons

\section{Corresponding author}

L. Xu, Medical College of Qingdao University, Qingdao, 266021 China. E-mail: xu.luo@163.com

\section{Introduction}

Nesfatin-1, the 82 amino acid cleavage product from nucleobindin-2 (NUCB2), is a recently discovered regulatory brain-gut peptide (Oh et al. 2006). Nesfatin-1 serves various roles in both in the central and peripheral nervous systems. Nesfatin-1 is widely distributed in the central nervous system (CNS) (Goebel-Stengel et al. 2011), with expression in several regions, including ventromedial hypothalamic nucleus (VMH) and hippocampus. Physiologically, nesfatin-1 inhibits nocturnal feeding behaviors and gastrointestinal motility in mice (Atsuchi et al. 2010) and also inhibits the release of gastric acid (Xia et al. 2012). Further, central injection of nesfatin-1 decreases gastric emptying of rats (Stengel et al. 2009b). Electrophysiological studies show that nesfatin-1 may exert its anorexic effect role via suppression of neuropeptide Y-expressing neurons in the hypothalamic arcuate nucleus (Price et al. 2008). Alternatively, corticotropin-releasing factor (CRF) receptor signaling, as well as oxytocin and $\alpha$-melanocytestimulating hormone ( $\alpha-\mathrm{MSH})$, are also important for appetite suppression (Tabarin et al. 2007) and may be involved in the inhibitory effects of nesfatin-1 on food 
intake and gastric motility.

The hippocampus is an important integrative relay station of the brain limbic system, involved in learning, memory and emotion. Many peptides involved in energy balance have been shown to be expressed in the hippocampus, including nesfatin-1 (Goebel-Stengel et al. 2011), CRF (Çalışkan et al. 2015) and leptin (Kim et al. 2015). Further, the hippocampus has been shown to be involved in digestive function (Chowdhury et al. 2014), through the processing of visceroceptive information mainly through reciprocally connections with hypothalamus, amygdala and medulla oblongata (Wenzel et al. 1976). The hypothalamus is essential for processing afferent signals from the gut as well as efferent signals that modulate energy balance (Snowball et al. 2000). $\mathrm{VMH}$ is essential for these processes, serving as the brain's "satiety center", as lesions of VMH causes hyperphagia and obesity (Schwartz et al. 2000).

Therefore, in the present study, we examined whether nesfatin-1 regulate the electrical activity of gastric distension (GD)-responsive neurons in $\mathrm{VMH}$, to explore whether nesfatin-1 exerts its influence on these neurons through an interaction with the CRF signaling pathway. Further, we investigated the role for hippocampal input to VMH on GD-responsive neuronal discharges.

\section{Methods}

\section{Experimental animals}

Adult male Wistar rats (250-300 g, provided by Qingdao Marine Drug Institution, Qingdao, Shandong, China) were used for the experiment. The rats were housed in a regulated environment $\left(22-28^{\circ} \mathrm{C}\right.$, exposed to lights on from 8:00 a.m. to 8:00 p.m.). Standard laboratory chow pellets and tap water were available ad libitum. All animal experiments were approved and performed in accordance with Institutional guidelines of the Animal Care and Use Committee (IACUC) at Qingdao University and IACUC has specifically approved this study.

\section{Retrograde tracing and immunohistochemistry}

Rats $(\mathrm{n}=5)$ were anesthetized with $10 \%$ chloral hydrate ( $3 \mathrm{ml} / \mathrm{kg}$, i.p., Sigma, St Louis, MO, USA) and anesthesia was confirmed by the absence of the paw pinch reflex. Each rat was positioned on a stereotaxic apparatus (Narashige SN-3, Tokyo, Japan) with its core temperature maintained at $\pm 37^{\circ} \mathrm{C}$ by a feedback- controlled heating pad. A single pressure injection of $0.1 \mu 13 \%$ (w/v) FG (Fluorochrome; Sigma, St. Louis, MO, USA; dissolved in distilled water) was made stereotaxically into the unilateral VMH (relative to bregma: posterior $2.28-2.64 \mathrm{~mm}$, lateral (right) 0.1-1.2 mm and depth $9.0-10.0 \mathrm{~mm}$ ) at coordinates derived from the atlas of Paxinos and Watson (2007). Seven days after the FG injection, the rats were perfused transaortically with $200 \mathrm{ml}$ of $0.9 \%$ saline, followed by $200 \mathrm{ml} 4 \% \quad(\mathrm{w} / \mathrm{v})$ paraformaldehyde solution in $0.1 \mathrm{M}$ phosphate buffer (PB; pH 7.4). The brain was removed immediately and postfixed for $4 \mathrm{~h}$ in $4 \%$ paraformaldehyde, then cryoprotected in $30 \%$ sucrose solution for 2 days at $4{ }^{\circ} \mathrm{C}$. The brain was cut serially into $15 \mu \mathrm{m}$ thick frontal sections on a freezing microtome (Kryostat 1720, Leica, Germany).

After the sections were incubated with primary nesfatin-1 (1-82, Rat) antibody (polyclonal; dilution $1: 300$; Phoenix Pharmaceuticals, Burlingame, CA, USA) at $4{ }^{\circ} \mathrm{C}$ for $40 \mathrm{~h}$, they were incubated with a fluorochrome-labeled secondary antibody (Cy3-conjugated goat anti-rabbit IgG; dilution $1: 500$; Jackson Immunoresearch, West Grove, PA, USA) for $2 \mathrm{~h}$. The sections were mounted with Citifluor (Citifluor, London, UK). All fluorophores were visualized and photographs were taken under a BX50 microscope and a DP50 digital camera (Olympus, Tokyo, Japan). Rats with inaccurate injection sites were eliminated from the study.

\section{Electrophysiology}

The rats $(\mathrm{n}=114)$, fasted for $18 \mathrm{~h}$, were anesthetized with $10 \%$ chloral hydrate $(0.3 \mathrm{ml}$ per $100 \mathrm{~g}$, i.p.). A small incision was made into the fundus after median laparotomy and the stomach was washed with warm isotonic saline. A latex balloon (3-4 $\mathrm{cm}$ in length) attached to polyethylene tubing (PE-240) was inserted into the stomach and fixed on the edge of the incision by a ligature to produce gastric distension by increasing the volume of the balloon $\left(3-5 \mathrm{ml} 37^{\circ} \mathrm{C}\right.$ water at a rate of $0.5 \mathrm{ml} / \mathrm{s}$ ) (Xu et al. 2008). Distension was maintained at a constant volume for 10-30 s. The pylorus was ligatured to avoid duodenal reflux and then the abdomen was closed.

In cranial surgery, the dorsal surface of the brain was exposed and the open part was covered with warm agar ( $3 \%$ in saline) to improve stability for neuronal recording. For micro-pressure injection and extracellular electrophysiological recording, a four-barrel glass microelectrode (total tip diameter 3-10 $\mu \mathrm{m}$, resistance 
5-20 M $\Omega$ ) was advanced in $10 \mu \mathrm{m}$ steps with the aid of hydraulic micropositioner into the area of $\mathrm{VMH}$ (position described as above). The recording glass microelectrode was filled with $0.5 \mathrm{M}$ sodium acetate and $2 \%$ pontamine sky blue. The other three barrels connected with a fourchannel pressure injector (PM2000B, Micro Data Instrument, Inc., USA) were filled with a $10 \mathrm{nM}$ solution of nesfatin-1 (1-82), a $200 \mathrm{nM}$ solution of astressin-B (Sigma, St Louis, MO, USA), a non-selective corticotropin-releasing factor (CRF) antagonist, or antiNUCB2/nesfatin-1 antibody (Phoenix Pharmaceuticals, Burlingame, CA, USA), and normal saline (NS), respectively. Drugs were ejected onto the surface of firing cells with short-pulse gas pressure (1500 ms, 5.0-15.0 psi) (Trudel et al. 2002).

Once the microelectrode was advanced into the $\mathrm{VMH}$, the extracellular action potentials of single neurons were recorded by the glass microelectrode (another electrode was placed on the epicranium of the rat), amplified using a high input impedance amplifier (MEZ8201, Nihon Kohden, Tokyo, Japan), and displayed on an oscilloscope (VC-11, Nihon Kohden, Tokyo, Japan). All signals measured with or without gastric distension were recorded and stored in a computer for further analyses. After a firing pattern was stabilized, the unit was tested with a GD stimulus to determine whether there was input from gastric mechanoreceptors. Units were then classified as gastric distension excitatory (GD-E) neurons if their spontaneous discharge was (transiently) increased in frequency by at least $20 \%$ during gastric distension, or as gastric distension inhibitory (GD-I) neurons when their frequency decreased by at least $20 \%$.

\section{Electrical stimulation and electrolytic lesion}

A monopolar stimulation electrode was advanced into the hippocampal CA1 region (relative to bregma: posterior 3.14-3.6 mm, lateral (right) $1.3-2.0 \mathrm{~mm}$ and depth 2.6-3.2 $\mathrm{mm}$ ) by bipolar concentric electrodes with an interpole distance of $0.5 \mathrm{~mm}$ and an external electrode diameter of $100 \mu \mathrm{m}$. Stimulation was from a stimulator with a radio-frequency output of square-wave current impulses, $20 \mu \mathrm{A}$ in intensity and $0.5 \mathrm{~ms}$ in duration, delivered for $10 \mathrm{~s}$ at $50 \mathrm{~Hz}$. Sham stimulation was conducted as the same procedure with the electrical stimulation but no current was passed through the electrode.

To identify the possible regulation of VMH by hippocampus, electrolytic lesions of the hippocampal
CA1 region were performed. In this experiment, 24 rats were randomly divided into 4 groups (6 rats for each group): sham lesion + NS group (SL+ NS), sham lesion + nesfatin-1 group (SL+ nesfatin-1), electrical lesion $+\mathrm{NS}$ group $(\mathrm{EL}+\mathrm{NS})$, electrical lesion + nesfatin-1 group $(\mathrm{EL}+$ nesfatin-1). The electrodes were delivered unilaterally to the CA1 region of the hippocampus by passing $1 \mathrm{~mA}$ of anodal direct current for $20 \mathrm{~s}$. Sham lesion was carried out according to the same procedure, without current passed through the electrode. All rats had 5 days recovery from the lesion procedure.

\section{Histological verification}

To check the position of the recording electrode, at the end of each experiment, a direct current $(10 \mu \mathrm{A}$, $20 \mathrm{~min}$ ) was passed through the electrode to form an iron deposit of Pontamine sky blue. After decapitation, brains were removed and postfixed in formalin for $4 \mathrm{~h}$. Coronal $50-\mu \mathrm{m}$ sections were cut on a freezing microtome and observed under a microscope. Rats with incorrect probe placements were excluded from analysis.

\section{Statistical analysis}

Data are presented as mean $\pm \mathrm{SD}$ and processed with SPSS 17.0 statistics software (IL, USA). Comparisons were made between groups by either Student's t-test (two groups only) or one-way analysis of variance followed by post-hoc Bonferroni's test for comparison among means. $P<0.05$ was considered as statistically significant.

\section{Results}

Dose-dependent effects of nesfatin-1 on discharge rate of GD-responsive neurons in $V M H$

First, we sought to establish a dose-dependent relationship between nesfatin-1 and the discharge rate of GD-responsive neurons in VMH. We tested a series of different concentration of nesfatin-1 $(0.5,1,5,10,50$, 100 and $150 \mathrm{nM}$ ), and showed that $0.5,1,5,10$ and $50 \mathrm{nM}$ nesfatin-1 significantly increased the discharge rate of GD-responsive neurons $(\mathrm{P}<0.05-0.01$, Fig. 1A). No significant differences between 50, 100, and $150 \mathrm{nM}$ nesfatin-1 were observed (Fig. 1A). $10 \mathrm{nM}$ nesfatin-1 produced a half-maximal response (pEC50, nesfatin-1). Next, the effect of nesfatin-1 on discharge duration of GD-responsive neurons was observed. We saw that 0.5-10 nM nesfatin-1 produced a dose-dependent increase in the duration of GD-responsive neuronal discharge 
$(\mathrm{P}<0.05 \sim 0.01$, Fig. 1B). However, when nesfatin-1 concentration was higher than $10 \mathrm{nM}$, the discharge time of the GD-responsive neurons was not markedly extended beyond the change induced by $10 \mathrm{nM}$ (Fig. 1B). Therefore, $10 \mathrm{nM}$ nesfatin-1 was used for the following experiments.
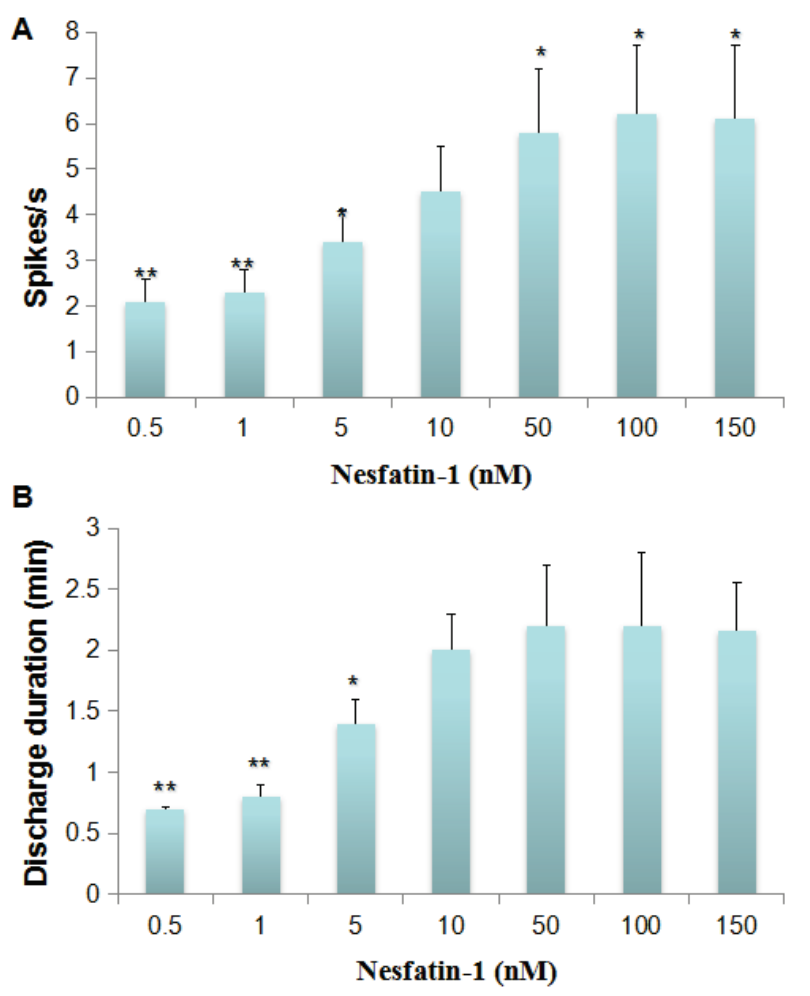

Fig. 1. Dose-dependent effects of nesfatin-1 on VMH GD-responsive neuronal discharge. (A) Effect of different concentrations of nesfatin- $1(0.5,1,5,10,50,100$ and $150 \mathrm{nM})$ on firing frequency of GD-responsive neurons. $* \mathrm{P}<0.05$, $* * \mathrm{P}<0.01$ vs. $10 \mathrm{nM}$ nesfatin-1. (B) Effect of different concentrations of nesfatin- $1(0.5,1,5,10,50,100$ and $150 \mathrm{nM})$ on the discharge duration of GD-responsive neurons. $* \mathrm{P}<0.05$, $* * \mathrm{P}<0.01$ vs. $10 \mathrm{nM}$ nesfatin- 1 .

Effects of nesfatin-1 on GD-responsive neuronal discharge in $\mathrm{VMH}$

Out of $182 \mathrm{VMH}$ neurons that were recorded from in 54 rats, $124(68.1 \%)$ responded to gastric distension and thus identified as GD-responsive neurons. Among these, the firing frequency of 65 GD-responsive neurons significantly increased and were classified as GD-E neurons $(\mathrm{P}<0.05 ; \quad$ Figs $2 \mathrm{~A}$ and $2 \mathrm{C})$; 59 GD-responsive neurons showed a decrease in firing rate and were classified as GD-I neurons $(\mathrm{P}<0.05$; Figs 2B and 2C).

When a GD-responsive neuron was confirmed, nesfatin-1 was microinjected into $\mathrm{VMH}$. Of $65 \mathrm{VMH}$ GD-E neurons examined, 25 (25/65, 38.5\%) showed a decrease in firing frequency in response to nesfatin-1 $(\mathrm{P}<0.05$, Figs $2 \mathrm{~A}$ and $2 \mathrm{C}), 18$ were activated, and 22 did not respond to nesfatin-1. 20 of 59 (20/59, $33.9 \%)$ GD-I neurons showed a significant increase in the firing frequency compared to saline treatment $(\mathrm{P}<0.05$, Figs $2 \mathrm{~B}$ and $2 \mathrm{C}$ ). Further, 16 were inhibited by nesfatin-1, and 23 did not respond. After pretreatment with the $\mathrm{CRF}$ antagonist astressin-B, the nesfatin-1-induced responses were partly abolished $(\mathrm{P}<0.05$, Fig. 2). Astressin-B alone had no effect on the activity of the GDresponsive neurons. A control injection of $0.9 \%$ saline was always carried out to confirm the specificity of the responses to nesfatin-1.

\section{FG/nesfatin-1 dual labeled neurons in hippocampus}

Next, we performed a retrograde tracing study by injecting FG into VMH. We observed FG-labeled neurons in the hippocampal CA1 region, seven days after injection (Figs 3A and 3D). In the same tissue, nesfatin-1 expression was assessed using a nesfatin-1 (1-82, Rat) antibody. Many nesfatin-1-immunoreactive neurons were observed in CA1 (Figs 3B and 3D), with some nesfatin-1positive neurons double-labeled with FG (Figs 3C and 3D), arguing that nesfatin-1-expressing neurons in $\mathrm{CA} 1$ send projections to $\mathrm{VMH}$.

Effects of hippocampal CA1 electrical stimulation on firing of VMH nesfatin-1/GD-responsive neurons

To observe the physiological relevance of this CA1-VMH connection on GD-responsive neurons, we recorded from VMH GD-responsive neurons during CA1 electrical stimulation. For these experiments, $208 \mathrm{VMH}$ neurons from 60 rats were recorded. 133 (63.9\%) were identified as GD-responsive neurons, out of 70 were GD-E neurons and 63 were GD-I neurons. 26 of 70 $(26 / 70,37.1 \%)$ GD-E neurons were suppressed by nesfatin-1 and 21 of 63 (21/63, 33.3\%) GD-I neurons showed increased firing rates induced by nesfatin-1. 14 out of $26(14 / 26,53.8 \%)$ GD-E neurons responsive to nesfatin-1 in the VMH were further excited by CA1 electrical stimulation ( $\mathrm{p}<0.01$, Figs $4 \mathrm{~A}$ and $4 \mathrm{C}$ ), 7 were inhibited and 5 had no response.

Out of 21 GD-I neurons responsive to nesfatin-1, $10(10 / 21,47.6 \%)$ were also excited by CA1 electrical stimulation $(\mathrm{p}<0.01$, Figs $4 \mathrm{~B}$ and $4 \mathrm{C})$, while 5 were inhibited and 6 had no change. Meanwhile, CA1 electrical stimulation-induced responses were inhibited by pre-treatment with anti-NUCB2/nesfatin-1 antibody to the $\mathrm{VMH}$ in either nesfatin-1-responsive GD-E (Figs 4A and 
$4 \mathrm{C}, \quad \mathrm{p}<0.05)$ or nesfatin-1-responsive GD-I neurons

(Figs $4 \mathrm{~B}$ and $4 \mathrm{C}, \mathrm{p}<0.05$ ). Injection of anti-NUCB2/ nesfatin-1 antibody alone did not change the firing activity of the nesfatin-1-responsive GD-E or GD-I neurons.
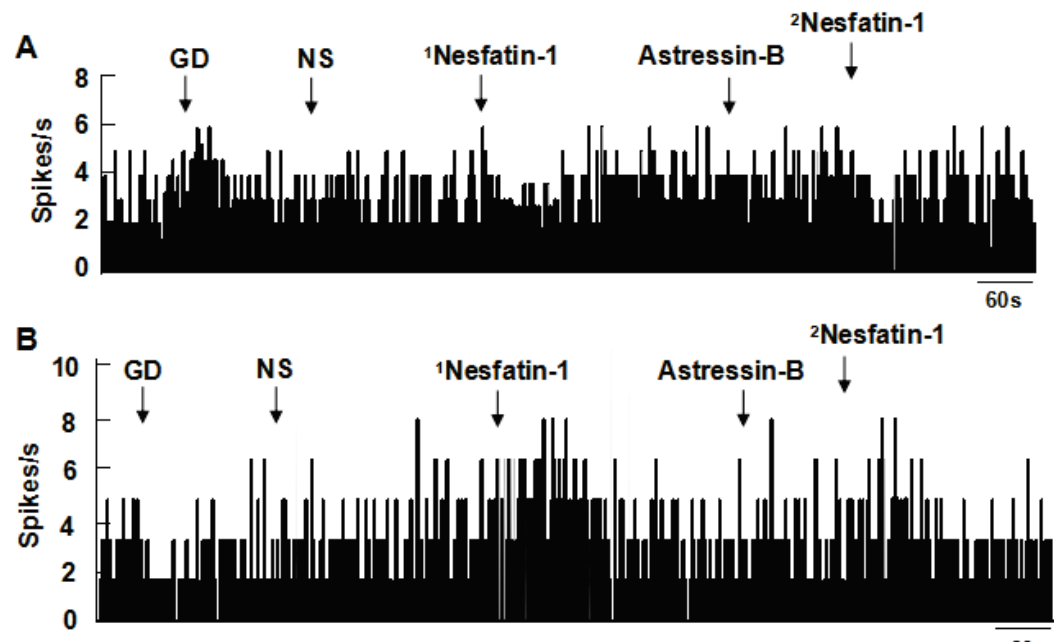

C
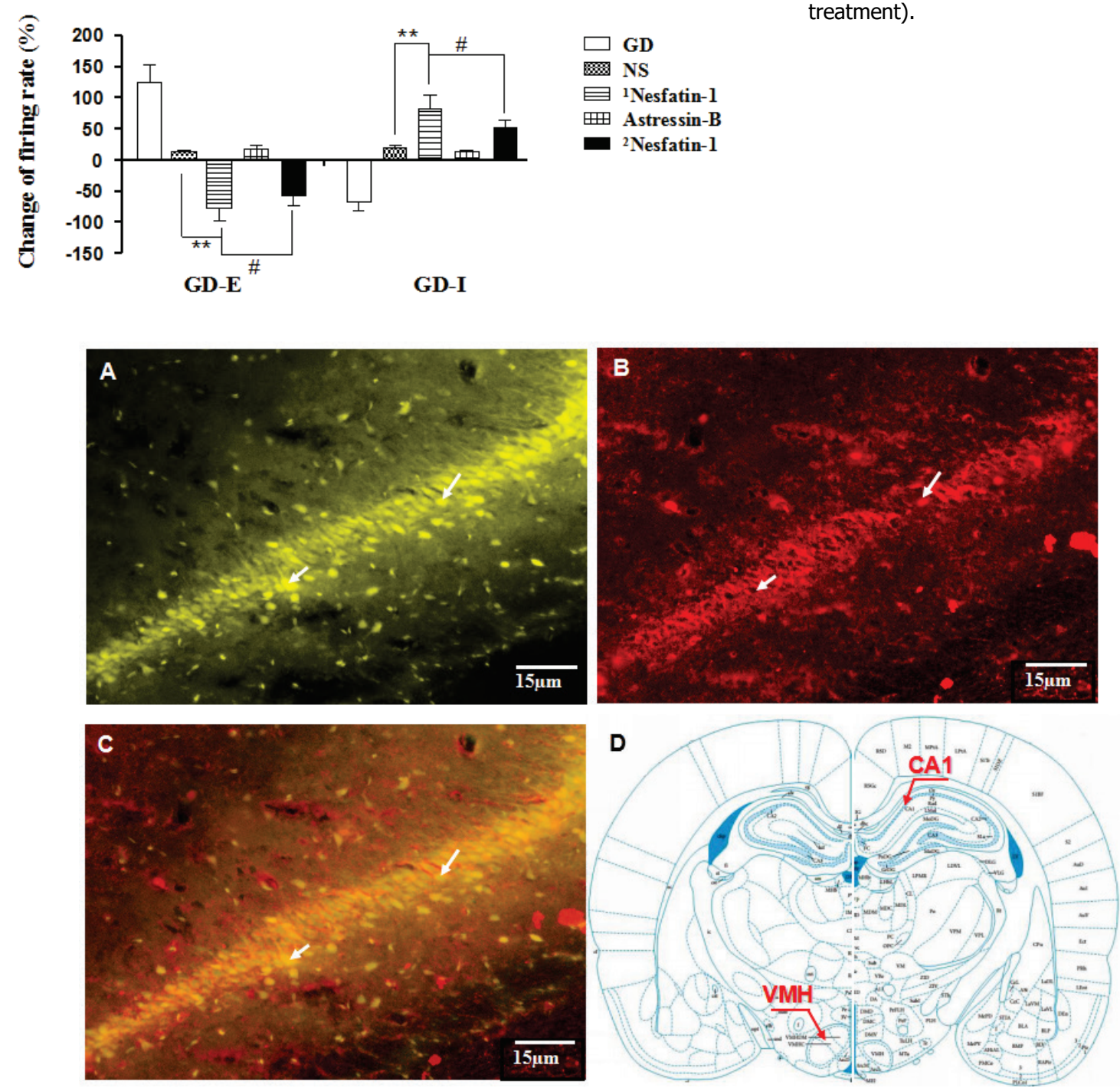

Fig. 3. FG/nesfatin-1 dual labeled neurons in hippocampal CA1 region. Seven days after FG injection in VMH, FG-labelled cells (A) and nesfatin-1-positive neurons (B) were found in the CA1 hippocampus by immunohistochemical staining of the same tissue. (C) Double visualization of FG-labelled cells and nesfatin-1-containing neurons in the hippocampal CA1. (D) A schematic diagram for the sites of the hippocampal CA1 region and VMH (Paxinos and Waston 2007). FG, fluorochrome; Scale bars $20 \mu \mathrm{m}$ (A-C).

Fig. 2. Effects of nesfatin-1 on the discharge of different types of GD-responsive neurons in VMH. Nesfatin-1 administration to VMH decreased the firing frequency of GD-E neurons (A) but increased the firing frequency of GD-I neurons (B). After pretreatment with astressin- $B$, the effects induced by nesfatin-1 were partially diminished. Normal saline or astressin-B alone had no effect on the firing frequency of neurons. (C) The change of firing rate (\%) of GD-responsive neurons in the VMH induced by nesfatin-1. Scale bar, $60 \mathrm{~s} .{ }^{*} * \mathrm{P}<0.01 \mathrm{vs}$. NS and $\# \mathrm{P}<0.05$ vs. ${ }^{1}$ nesfatin-1. Data are showed as mean \pm SD. The change of firing rate of GD-responsive neurons was calculated by $100 \times$ (firing rate of GD-responsive neurons after treatment - firing rate of GD-responsive neurons before treatment)/ (firing rate of GD-responsive neurons before treatment). 


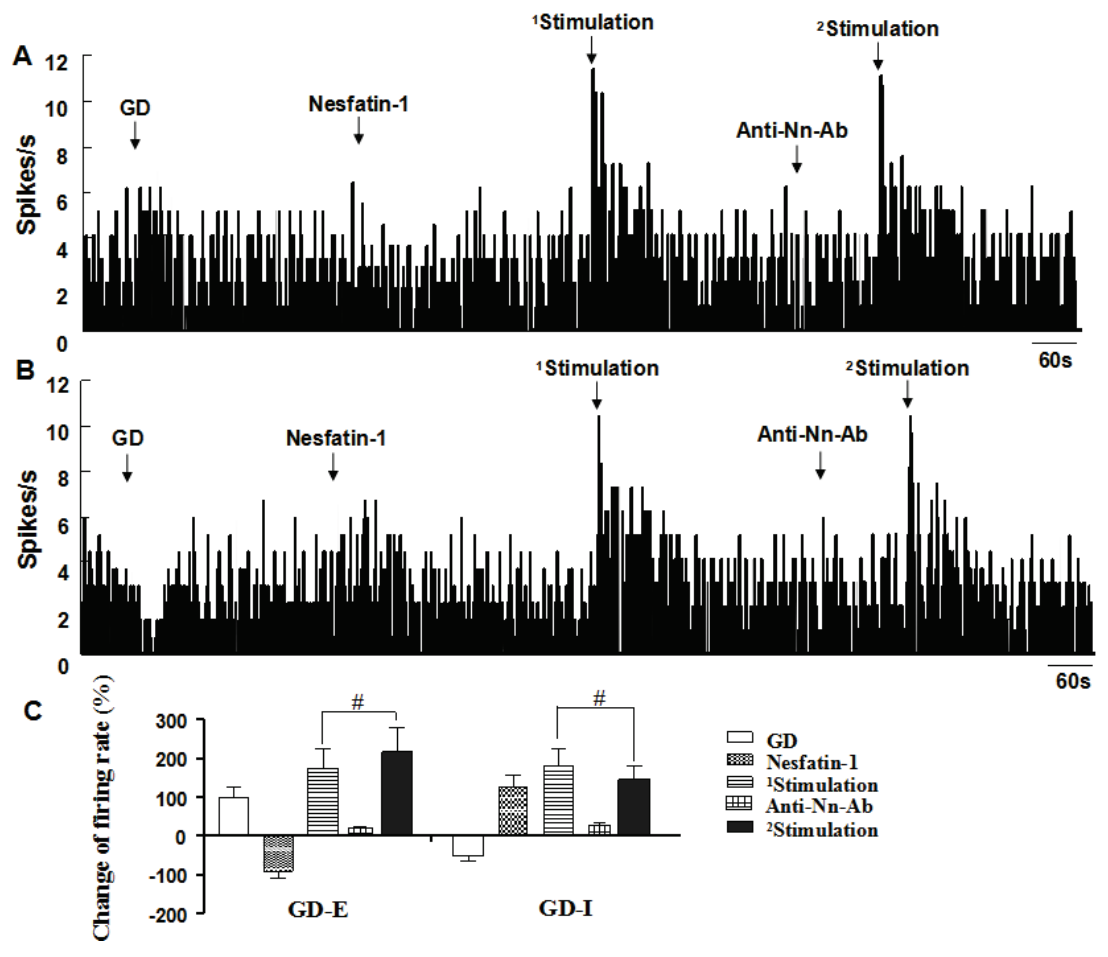

Fig. 4. Effects of CA1 electrical stimulation on dischargeof nesfatin-1/GD-responsive neurons in $\mathrm{VMH}$. Both nesfatin-1-responsive GD-E neurons (A) and GD-I neurons (B) were excited by electrical stimulation of the hippocampal CA1 region. However, pretreatment with aNUCB2/nesfatin-1 antibody in the VMH partially diminished the increases induced by CA1 stimulation. Scale bar, 60 s. (C) The change infiring rate (\%) of nesfatin-1-responsive GD neurons in $\mathrm{VMH}$ induced by electrical stimulation of the hippocampal CA1 region. $\# P<0.05$ vs. ${ }^{1}$ stimulation. Data are showed as mean \pm SD. Anti-Nn-Ab, anti-NUCB2/nesfatin-1 antibody.
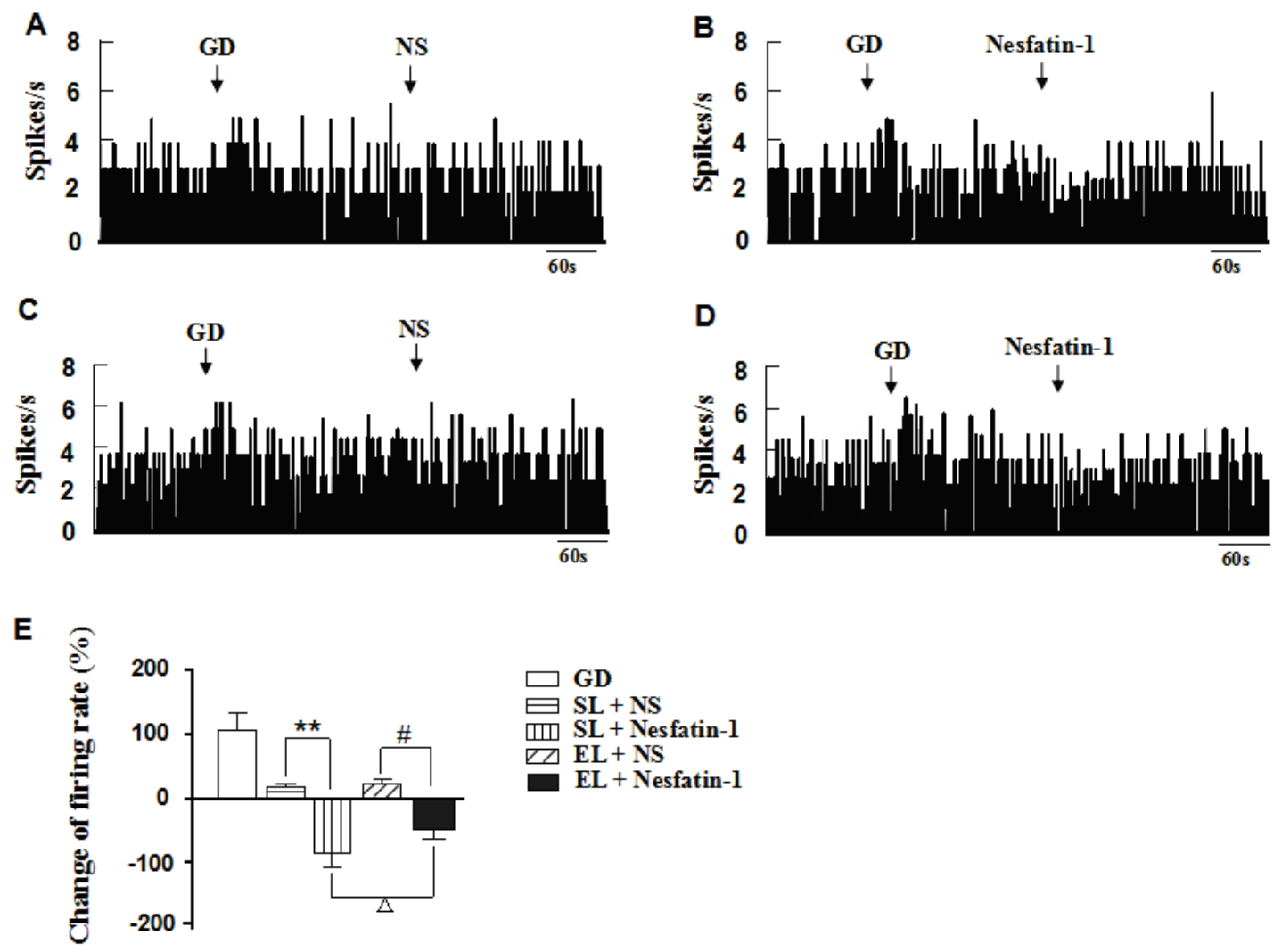

Fig. 5. Effects of elecrolytic lesion of CA1 hippocampus on GD-responsive neuronal firing. (A) Sham lesion + NS group (SL+NS); (B) Sham lesion + nesfatin-1 group (SL+nesfatin-1); (C) Electrical lesion + NS group (EL+NS); (D) Electrical lesion + nesfatin-1 group (EL+nesfatin-1). The results showed that the discharge of GD-responsive neurons in VMH did not markedly change after CA1 lesion. However, the firing of GD-responsive neurons was reduced by nesfatin-1 administration to $\mathrm{VMH}$ in the hippocampal lesionedrats compared with the sham lesion + nesfatin-1 group $(B, D)$. (E) Changes in percent firing rate (\%) of GD-responsive neurons in VMH induced by electrical lesion of the hippocampal CA1 region. ${ }^{* * P}<0.01$ vs. SL+NS. \#P<0.05 vs. EL+NS. $\Delta \mathrm{P}<0.05$ vs. SL+nesfatin-1. 
Effects of CA1 electrolytic lesion on VMH GD-responsive neurons

To further characterize CA1 regulation of $\mathrm{VMH}$ GD-responsive neuronal discharges, we electrically lesioned CA1 prior to VMH recordings. CA1 lesion, alone, did not affect the firing of VMH GD-responsive neurons. The effect of the nesfatin-1 on VMH GD-responsive neurons were significantly reduced in CA1 lesioned rats compared with sham lesioned rats ( $\mathrm{P}<0.05$, Fig. 5).

\section{Discussion}

The present study demonstrates that nesfatin-1 administration to VMH decreases the firing rate of GD-E neurons and increases firing rate of GD-I neurons via an interaction with the CRF signaling pathway. Electrical stimulation of the CA1 region of hippocampus caused excitation of VMH nesfatin-1/GD-responsive neurons. Further, the effect of nesfatin-1 on GD-responsive neurons in the VMH was weakened following electrolytic lesion of CA1. The effect of CA1 electrical stimulation on VMH nesfatin-1/GD-responsive neurons were partially blocked by pretreatment with an anti-NUCB2/ nesfatin-1 antibody in VMH. Furthermore, our retrograde tracing and immunohistochemical staining revealed FG/nesfatin-1 double labeled neurons in CA1 region following $\mathrm{FG}$ injection of $\mathrm{VMH}$. Thus, we infer that hippocampal nestfatin-1 neurons modulate the activity of $\mathrm{VMH}$. It follows that nesfatin-1-expressing neurons in the hippocampus project to $\mathrm{VMH}$ and are involved in the regulation of gastric motility.

Nesfatin-1 is a novel anorexigenic peptide, cleaved from the larger protein nucleobindin-2 (NUCB2) (Oh et al. 2006). Nesfatin-1 displays low expression levels in the hypothalamic paraventricular nucleus after fasting. In rats, the mRNA and protein levels of NUCB2/nesfatin-1 are more prominently expressed in the gastric oxyntic mucosa (Stengel et al. 2009a). The effect of nesfatin-1 on gastrointestinal mobility and its role in the regulation of food intake are well known, but the receptor signaling mechanisms and gastrointestinal tract mediating these actions remains unknown. Recent studies demonstrate that nesfatin-1 can cross the blood-brain barrier in both directions in a non-saturable manner (Pan et al. 2007). Thus, we investigated whether the administration of nesfatin-1 to the brain affects the regulation of gastrointestinal function. Our study shows that nesfatin-1 regulates GD-responsive neurons in the $\mathrm{VMH}$, neurons that receive afferent signals from the stomach. It is thus implied that central nesfatin-1 may be involved in the regulation of gastric activity.

For many years, VMH has been recognized for its role in processing satiety signals and regulating ingestive behavior and body weight. The VMH has a particularly large number of glucoresponsive neurons, which dynamically respond to hypoglycemia (Routh et al. 2003). Recent research has shown that several receptor signaling systems in $\mathrm{VMH}$, including dopamine (Huang et al. 2005), GABA (Dellovade et al. 2001), histamine (Magrani et al. 2004) impact feeding behavior. In our study, we found neurons sensitive to gastric distension sensitive in VMH. We infer that VMH may have a role in the modulation gastric motility. Anatomically, VMH makes connections with many brain regions that are associated with feeding behavior. We used gastric distension as a stimulus of visceral afferent signals because it is a relatively specific and homogeneous class of vagal afferent signal related to food ingestion (Tache et al. 2008). Our data indicate that VMH receives this signal from the gastrointestinal tract. We show that administration of exogenous nesfatin-1 to VMH decreases the activity of GD-E neurons, but increase the activity of GD-I neurons. The anorexigenic action of nesfatin-1 may be related to these changes in the activity of GD-responsive neurons. This point can be confirmed by future experiments.

NUCB2/nesfatin-1-immunoreactive neurons co-express several other peptides and neurotransmitters, which are known to be involved with the regulation of food intake, namely corticotropin-releasing factor (CRF) (Foo et al. 2008), a-melanocyte-stimulating hormone ( $\alpha$-MSH) (Fort et al. 2008), ghrelin (Kerbel and Unniappan 2008), as well as many others. In particular, brain CRF is involved in the stress-induced suppression of gastric motility (Stengel and Taché 2009). Further, circulating levels of both corticosterone and adrenocorticotropin $(\mathrm{ACTH})$ are elevated following intracerebroventricular injection (ICV) administration of nesfatin-1, both of which are essential for hypothalamic-pituitary-adrenal axis function (Konczol et al. 2010). Furthermore, bilateral adrenalectomy increases the expression of NUCB2/nesfatin-1 mRNA in the paraventricular hypothalamic nucleus (PVN) (Shimizu et al. 2009). CRF receptor related peptides are involved in numerous physiological and behavioral functions, including gastrointestinal regulation. They are also capable of strong 
anorectic and thermogenic effects. In fact, the CRF system, which promotes a negative energy profile upon activation, could represent a potential target for the pharmacological treatment of obesity. CRF receptor-expressing neurons in $\mathrm{VMH}$ seem to be involved in the regulation of energy intake, maintaining homeostatic steady state (Doyon et al. 2004). Injection of CRF receptor antagonists counteracts the anorexigenic function of nesfatin-1 (Gotoh et al. 2013). Stimulation of the CRF receptor in the VMH decreases feeding. Further, a negative metabolic state or hyperphagia are associated with decreased expression of CRF receptors in the VMH (Hashimoto et al. 2004, Makino et al. 1998). In the present study, we have shown that the effects of nesfatin-1 on GD-sensitive neurons could be partially abolished by pretreatment with the CRF non-selective antagonist astressin-B in the VMH. Thus, we hypothesize that nesfatin-1 exerts its anorexigenic effect via the CRF receptor signaling pathway in the VMH. This functional relationship between nesfatin-1 and the CRF signaling system may have implications in the understanding of gastrointestinal function disorders and obesity.

In recent years, the hippocampus has received much attention in relation to its potential involvement in feeding and energy regulation (Wang et al. 2006). This focus is partly based on the fact that many receptors for neurohormonal signaling molecules, including ghrelin, cholecystokinin, leptin, insulin, are expressed in hippocampus (Davidson et al. 2009). Anatomically, direct neural projections from the ventral pole of the hippocampal CA1 to hypothalamic loci known to participate in the control of food intake have been identified (Cenquizca et al. 2006). Also, hippocampal lesion has been shown to alter feeding behavior in rats (Clifton et al. 1998). Our study found that VMH GD-responsive neuronal discharges were enhanced by administration of nesfatin-1 following electrical stimulation of CA1. This result suggests that the hippocampus is able to regulate the activity of $\mathrm{VMH}$ neurons. The retrograde tracing and fluoroimmunohistochemical staining studies confirmed the nesfatin-1-expressing neurons make connections from CA1 to VMH.

Taking together, our data suggest that nesfatin-1 release in VMH modulates GD-responsive neurons, perhaps via CRF signaling pathways. Further, the hippocampus participates in this process. These studies provide insight into the role of $\mathrm{VMH}$ in the control of gastrointestinal function mediated via nesfatin-1.

\section{Conflict of Interest}

There is no conflict of interest.

\section{Acknowledgements}

This work was supported by the National Natural Science Foundation of China (No.81470815, No.81500414, No.81100260, No.81270460 and No.81300281); Research Award Fund for Outstanding Middle-aged and Young Scientist of Shandong Province (No. BS2014YY009); Shandong Province Natural Science Foundation (ZR2014CM014); Qingdao Municipal Science and Technology Commission (14-2-3-3-nsh).

\section{References}

ATSUCHI K, ASAKAWA A, USHIKAI M, ATAKA K, TSAI M, KOYAMA K, SATO Y, KATO I, FUJIMIYA M, INUI A: Centrally administered nesfatin-1 inhibits feeding behaviour and gastroduodenal motility in mice. Neuroreport 21: 1008-1011, 2010.

ÇALISKAN G, SCHULZ SB, GRUBER D, BEHR J, HEINEMANN U, GEREVICH Z: Corticosterone and corticotropin-releasing factor acutely facilitate gamma oscillations in the hippocampus in vitro. Eur J Neurosci 41: $31-44,2015$.

CENQUIZCA LA, SWANSON LW: Analysis of direct hippocampal cortical field CA1 axonal projections to diencephalon in the rat. $J$ Comp Neurol 497: 101-114, 2006.

CHOWDHURY TG, RIOS MB, CHAN TE, CASSATARO DS, BARBARICH-MARSTELLER NC, AOKI C: Activity-based anorexia during adolescence disrupts normal development of the CA1 pyramidal cells in the ventral hippocampus of female rats. Hippocampus 24: 1421-1429, 2014.

CLIFTON PG, VICKERS SP, SOMERVILLE EM: Little and often: ingestive behavior patterns following hippocampal lesions in rats. Behav Neurosci 112: 502-511, 1998.

DAVIDSON TL, CHAN K, JARRARD LE, KANOSKI SE, CLEGG DJ, STEPHEN C: Benoit 4 contributions of the hippocampus and medial prefrontal cortex to energy and body weight regulation. Hippocampus 19: 235-252, 2009. 
DELLOVADE TL, DAVIS AM, FERGUSON C, SIEGHART W, HUMANICS GE, TOBET SA: GABA influences the development of the ventromedial nucleus of the hypothalamus. J Neurobiol 49: 264-276, 2001.

DOYON C, MORARU A, RICHARD D: The corticotropin-releasing factor system as a potential target for antiobesity drugs. Drug News Perspect 17: 505-517, 2004.

FOO K, BRISMAR H, BROBERGER C: Distribution and neuropeptide coexistence of nucleobindin-2 mRNA/nesfatinlike immunoreactivity in the rat CNS. Neuroscience 156: 563-579, 2008.

FORT P, SALVERT D, HANRIOT L, JEGO S, SHIMIZU H, HASHIMOTO K: The satiety molecule nesfatin-1 is co-expressed with melanin concentrating hormone in tuberal hypothalamic neurones of the rat. Neuroscience 155: 174-181, 2008.

GOEBEL-STENGEL M, WANG LX, STENGEL A, TACHE Y: Localization of nesfatin-1 neurones in the mouse brain and functional implication. Brain Res 1396C: 20-34, 2011.

GOTOH K, MASAKI T, CHIBA S, ANDO H, SHIMASAKI T, MITSUTOMI K: Nesfatin-1, corticotropinreleasing hormone, thyrotropin-releasing hormone, and neuronal histamine interact in the hypothalamus to regulate feeding behavior. J Neurochem 124: 90-99, 2013.

HASHIMOTO K, NISHIYAMA M, TANAKA Y, NOGUCHI T, ASABA K, HOSSEIN PN, NISHIOKA T, MAKINO $\mathrm{S}$ : Urocortins and corticotropin releasing factor type 2 receptors in the hypothalamus and the cardiovascular system. Peptides 25: 1711-1721, 2004.

HUANG XF, YU Y, ZAVITSANOU K, HAN M, STORLIEN L: Differential expression of dopamine D2 and D4 receptor and tyrosine hydroxylase mRNA in mice prone, or resistant, to chronic high-fat diet-induced obesity. Brain Res Mol Brain Res 135: 150-161, 2005.

KERBEL B, UNNIAPPAN S: Nesfatin-1 suppresses energy intake, co-localises ghrelin in the brain and gut, and alters ghrelin, cholecystokinin and orexin mRNA expression in goldfish. J Neuroendocrinol 24: 366-377, 2012.

KIM Y, KIM S, KIM C, SATO T, KOJIMA M, PARK S: Ghrelin is required for dietary restriction-induced enhancement of hippocampal neurogenesis: lessons from ghrelin knockout mice. Endocr J 62: 269-275, 2015.

KONCZOL K, BODNAR I, ZELENA D, PINTER O, PAPP RS, PALKOVITS M, NAGY GM, TOTH ZE: Nesfatin-1/NUCB2 may participate in the activation of the hypothalamic-pituitary-adrenal axis in rats. Neurochem Int 57: 189-197, 2010.

MAKINO S, NISHIYAMA M, ASABA K, GOLD PW, HASHIMOTO K: Altered expression of type 2 CRH receptor mRNA in the VMH by glucocorticoids and starvation. Am J Physiol 275: R1138-R1145, 1998.

MAGRANi J, DE CASTRO E SILVA E, VARJAO B, DUARTE G, RAMOS AC, ATHANAZIO R, BARBETTA M, LUZ P, FREGONEZE JB: Histaminergic $\mathrm{H} 1$ and $\mathrm{H} 2$ receptors located within the ventromedial hypothalamus regulate food and water intake in rats. Pharmacol Biochem Behav 79: 189-198, 2004.

OH IS, SHIMIZU H, SATOH T, OKADA S, ADACHI S, INOUE K, EGUCHI H, YAMAMOTO M, IMAKI T, HASHIMOTO K, TSUCHIYA T, MONDEN T, HORIGUCHI K, YAMADA M, MORI M: Identification of NUCB2/nesfatin-1 as a satiety molecule in the hypothalamus. Nature 443: 709-712, 2006.

PAN WH, HUNG HC, ABBA JK: Nesfatin-1 crosses the blood-brain barrier without saturation. Peptides 28: 2223-2228, 2007.

PAXINOS G, WATSON C: The Rat Brain in Stereotaxic Coordinates. Academic Press Inc., San Diego, CA, USA, 2007.

PILLY PK, GROSSBERG S: How do spatial learning and memory occur in the brain? Coordinated learning of entorhinal grid cells and hippocampal place cells. J Cogn Neurosci 24: 1031-1054, 2012.

PRICE CJ, SAMSON WK, FERGUSON AV: Nesfatin-1 inhibits NPY neurons in the arcuate nucleus. Brain Res 16: 99-106, 2008.

ROUTH VH: Glucosensing neurons in the ventromedial hypothalamic nucleus (VMN) and hypoglycemia-associated autonomic failure (HAAF). Diabetes Metab Res Rev 19: 348-356, 2003.

SCHWARTZ MW, WOODS SC, PORTE D JR, SEELEY RJ, BASKIN DG: Central nervous system control of food intake. Nature 404: 661-671, 2000.

SHIMIZU H, OH IS, OKADA S, MORI M: Nesfatin-1: an overview and future clinical application. Endocr $J$ 56: 537-543, 2009. 
SNOWBALL RK, SEMENENKO FM, LUMB BM: Visceral inputs to neurons in the anterior hypothalamus including those that project to the periaqueductal gray: a functional anatomical and electrophysiologic study. Neuroscience 99: 351-361, 2000.

STENGEL A, TACHE Y: Neuroendocrine control of the gut during stress: corticotropin-releasing factor signaling pathways in the spotlight. Annu Rev Physiol 71: 219-239, 2009.

STENGEL A, GOEBEL M, YAKUBOV I, WANG L, WITCHER D, COSKUN T, TACHE Y, SACHS G, LAMBRECHT NW: Identification and characterization of nesfatin-1 immunoreactivity in endocrine cell types of the rat gastric oxyntic mucosa. Endocrinology 150: 232-238, 2009a.

STENGEL A, GOEBEL M, WANG L, RIVIER J, KOBELT P, MONNIKES H, LAMBRECHT NW, TACHE Y: Central NUCB2/nesfatin-1 reduces dark-phase food intake and gastric emptying in rats: differential role of corticotropin-releasing factor2 receptor. Endocrinology 150: 4911-4919, 2009b.

TABARIN A, DIZ-CHAVES Y, CONSOLI D, MONSAINGEON M, BALE TL, CULLER MD, DATTA R, DRAGO F, VALE WW, KOOB GF, ZORRILLA EP, CONTARINO A: Role of the corticotropin-releasing factor receptor type 2 in the control of food intake in mice: a meal pattern analysis. Eur J Neurosci 26: 2303-2314, 2007.

TACHE Y, GARRICK T, RAYBOULD H: Central nervous system action of peptides to influence gastrointestinal motor function. Gastroenterology 98: 517-528, 2008.

TRUDEL L, TOMASETTO C, RIO MC, BOUIN M, PLOURDE V, EBERLING P, POITRAS P: Ghrelin/motilinrelated peptide is a potent prokinetic to reverse gastric postoperative ileus in rat. Am J Physiol Gastrointest Liver Physiol 282: G948-G952, 2002.

WANG GJ, YANG J, VOLKOW ND, TELANG F, MA Y, ZHU W, WONG CT, TOMASI D, THANOS PK, FOWLER JS: Gastric stimulation in obese subjects activates the hippocampus and other regions involved in brain reward circuitry. Proc Natl Acad Sci USA 103: 15641-15645, 2006.

WENZEL J, BOGOLEPOV NN: Electronmicroscopical and morphometrical study of rat hippocampal synapses. J Hirnforsch 17: 399-448, 1976.

XIA ZF, FRITZE DM, LI JY, CHAI B, ZHANG C, ZHANG W, MULHOLLAND MW: Nesfatin-1 inhibits gastric acid secretion via a central vagal mechanism in rats. Am J Physiol Gastrointest Liver Physiol 303: G570-G577, 2012.

XU L, SUN X, DEPOORTERE I, LU J, GUO F, PEETERS TL: Effect of motilin on the discharge of rat hippocampal neurones responding to gastric distension and its potential mechanism. Peptides 29: 585-592, 2008. 